\section{Chat shows}

\section{Passionate Minds: The Inner World of Scientists}

by Lewis Wolpert and Alison Richards Oxford University Press:1997. Pp. 240.

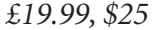

\section{A Glorious Accident: Understanding Our Place in the Cosmic Puzzle} by Wim Kayzer

W. H. Freeman: 1997. Pp. 306. \$24.95, $\mathfrak{E} 17.95$

\section{Peter Atkins}

Scratching a scientist reveals a human within. But how do humans who have made such extraordinary contributions to our understanding of the world differ from the rest of us? Lewis Wolpert set out, in the company of his producer Alison Richards, to expose the fire in the bellies of a clutch of substantial scientists. The television programmes they compiled are transcribed into two dozen short chapters in this engaging volume.

Their guests included Carl Djerassi, who with his synthesis of the first steroid contraceptive has probably done more for the liberation of humanity than any other chemist, Gerald Edelman, Murray Gell-Mann and James Black, whose work on receptor blockers has saved thousands of lives. Inevitably, I suppose, as they were seeking the established, reputed scientists of the late twentieth century, their guest list is late-middle-aged and dominated by men.

I was enthralled by the encapsulated biographies tweaked from their vessels by conversational nudges from Wolpert, who delicately and unobtrusively guides the conversations in directions that provide sometimes charming, sometimes deep insights into the springs of creativity. Determination and bloody-mindedness played a part in many of their lives, along with the ability to stand out against the flow of contemporary thought and ask questions that might be thought absurd but turned out to be amazingly fruitful. Of course, the raising of seemingly absurd questions is not on its own a sufficient condition for substantial discovery: if it were, all of us would have won Nobel prizes. Here we see seeming absurdity in the matrix of intelligence, application and talent.

\section{New in paperback}

\author{
The Fabric of Reality \\ by David Deutsch \\ Penguin, £8.99 \\ Reviewed in Nature 388, 136 (1997). \\ Brainchildren: Essays on \\ Designing Minds \\ by Daniel C. Dennett \\ Penguin, $£ 12.50$
}

I found a delight on every page, and warmly recommend this book to anyone with an interest in the human side of science, and not only that, for the speakers' own assessment of their achievements - for the most part modest, but throughout with a discernible and proper edge of pride introduces us to their science in the gentlest possible way. I enjoyed travelling with Jared Diamond through New Guinea and listening to him robustly defending mere collectors of information (which he is not), and brushing out fossils with Elwyn Simons, as much as I enjoyed following Sheldon Glashow and Carlo Rubbia through the tangled history of the seminal contributions to our cosmic foundations that particle physics represents. In short, this book is a hugely enjoyable and instructive read.

The collection of interviews introduced and edited by Wim Kayzer also grew from another medium: they are a companion to a television series first shown in the Netherlands but also shown in the United States. Kayzer, whom Stephen Jay Gould so often brands as a romantic, had the idea of assembling some 'Great Brains' around a table, like a latter-day Ottoline Morrell, and watching what happened. That was the television component. To provide a background to the series, Kayzer ferreted around in the backgrounds of his contributors and, through a series of individual interviews that make up the bulk of this book, sought, like Wolpert in his, to bare the personal springs of public achievements.

The assembled Brains are those of Oliver Sacks, Stephen Jay Gould, Daniel Dennett, Freeman Dyson, Rupert Sheldrake and Stephen Toulmin. I think it regrettable that Sheldrake was invited, for any airing of absurd views adds to their life; but he is despatched with finesse by the orthodox team, and their general scepticism turns out to be a portrayal of real science in action. The remaining Brains span the cultures of the enterprise: Sacks erudite but whimsical, Gould acerbic but focused, Dennett imaginative and trenchant, Dyson precise and informed, and Toulmin cultured and circumspect.

All the interviews reveal the inner world of the participants, and in that respect Kayzer's book is an interesting complement to that of Wolpert and Richards. Two inter-

Collection of previously published essays by the garrulous Tufts University philosopher

The Very First Light: A Scientific Journey Back to the Dawn of the Universe

by John C. Mather and John Boslough

Penguin, $£ 8.99$

Reviewed in Nature 385, 691 (1997). views stand out and leave a lasting impression. The first is Dyson's account of his migration from pacifism in the 1930s to being a contributing agent to countless deaths (and almost certainly the saviour of countless more) during the Second World War, and is moving for its honesty. I am not sure that it makes him 'human' in the generally accepted sense of the term, but it certainly adds a dimension to my understanding of this extraordinarily imaginative and talented man. The other outstanding interview is that with Gould, who plainly hated every second of it, and Kayzer had to drag the conversation out of him. The result is pure gold: pithy, acerbic and intelligent, with an occasional burst of words when exasperation got the upper hand and led to a torrent of truths being unleashed.

Gould maintains his role as guard of the rational and scourge of the soppy in the transcription of the discussion that follows. The discussion fulfilled Kayzer's original romantic dream of overhearing Brains at play in the sandpit of discussion. The Brains gossip eruditely and with spirit about some vaguely 'unanswerable' questions, such as the current 'Top Question' - the nature of consciousness - and some lesser, more readily answerable questions, such as what keeps the Brains spellbound today.

What keeps brains, as distinct from Brains, spellbound is of course the stuff of science, and these two books put such valuable insights into the process into the hands of the general reader. They are two thoroughly good and entertaining reads.

Peter Atkins is at Lincoln College, Oxford OX1 3DR, UK.

\section{New Journals}

This year, Nature's annual new journals review supplement will appear in the issue of 10 September. Publishers and learned societies are invited to submit journals for review, as well as details of any eligible electronic journals, taking note of the following criteria:

- Journals must have first appeared during or after June 1996 and issued at least four separate numbers by the end of May 1998. - Journals covering any aspect of science are eligible, although those dealing with clinical medicine and pure mathematics are excluded, as are newsletters and publications of abstracts.

- Frequency of publication must be at least three times a year.

- The main language is English.

- Deadline for submission is 5 June.

Please send at least four different issues (the first, the most recent and any two others) of each eligible title, together with full details of subscription rates, to: Peter Tallack, Nature, Porters South, Crinan Street, London N1 9XW, UK. Tel: +44 (0)171 843 4567.e-mail: p.tallack@nature.com 